\title{
perforaciones para cimientos
}

$866 \cdot 18$

La economía general tiene actualmente una influencia decisiva en obra y taller. Al considerar las múltiples y complejas modalidades de apoyar una estructura sobre el terreno de sustentación se presenta el problema de abrir zanjas, rellenarlas parcialmente de mamposterías, generalmente ciclópeas, o con hormigón, y rellenar después las partes huecas que han quedado de las zanjas con las tierras que se habían excavado.

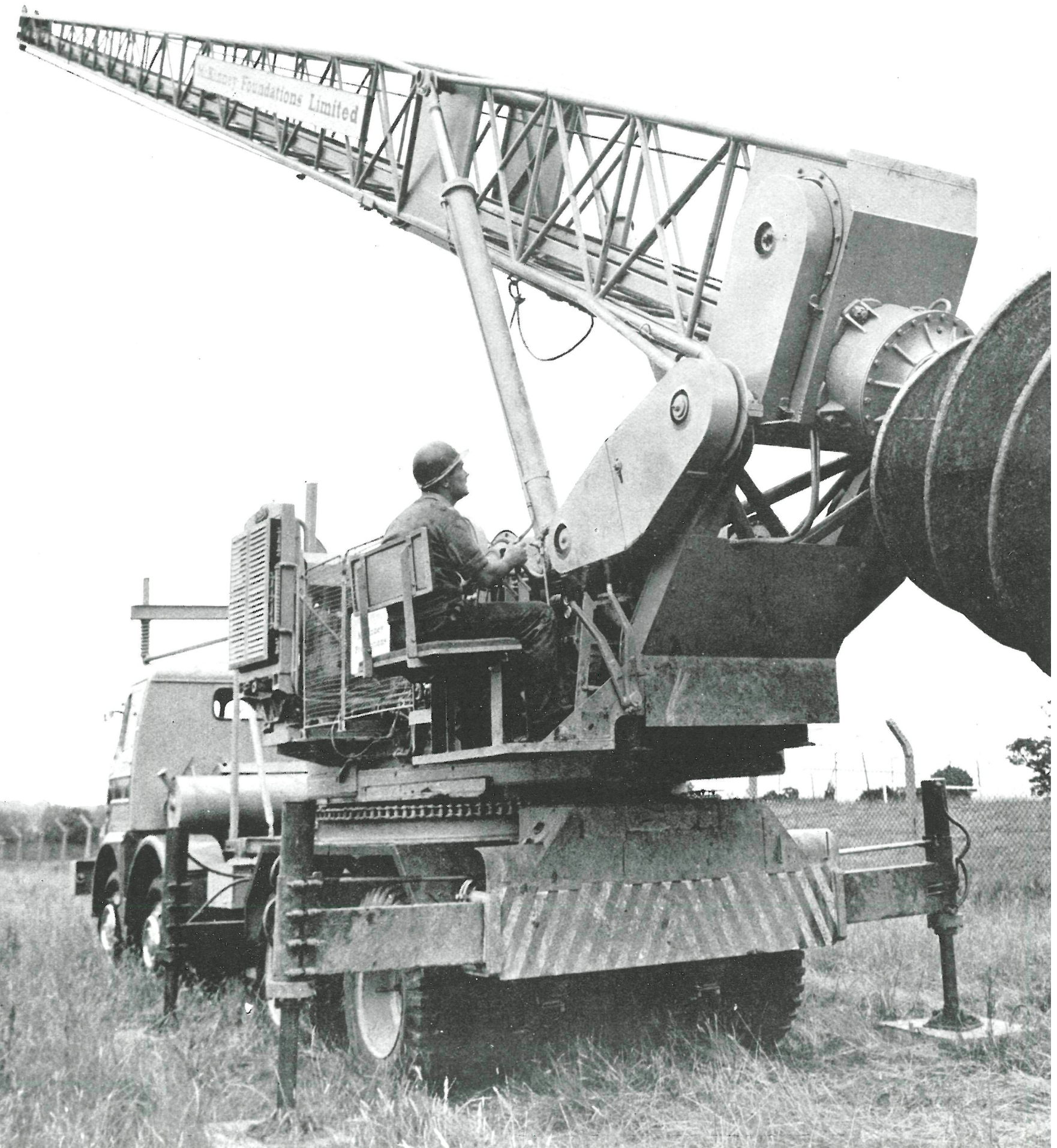


La casa M c Kinney Foundations Limited, de Borehamwood de Herts (Inglaterra), en relación directa con otras empresas americanas especializadas en perforaciones para cimientos, y formando grupo con el conjunto John Laing and Son Limited, ha lanzado al mercado un tipo especial de tren de perforaciones, de gran diámetro, en terrenos blandos o semiblandos, que está llamado a prestar una valiosa ayuda cuando se trata de cimientos formando palizadas de pilotes o lo que se conoce con el nombre de pocillos.
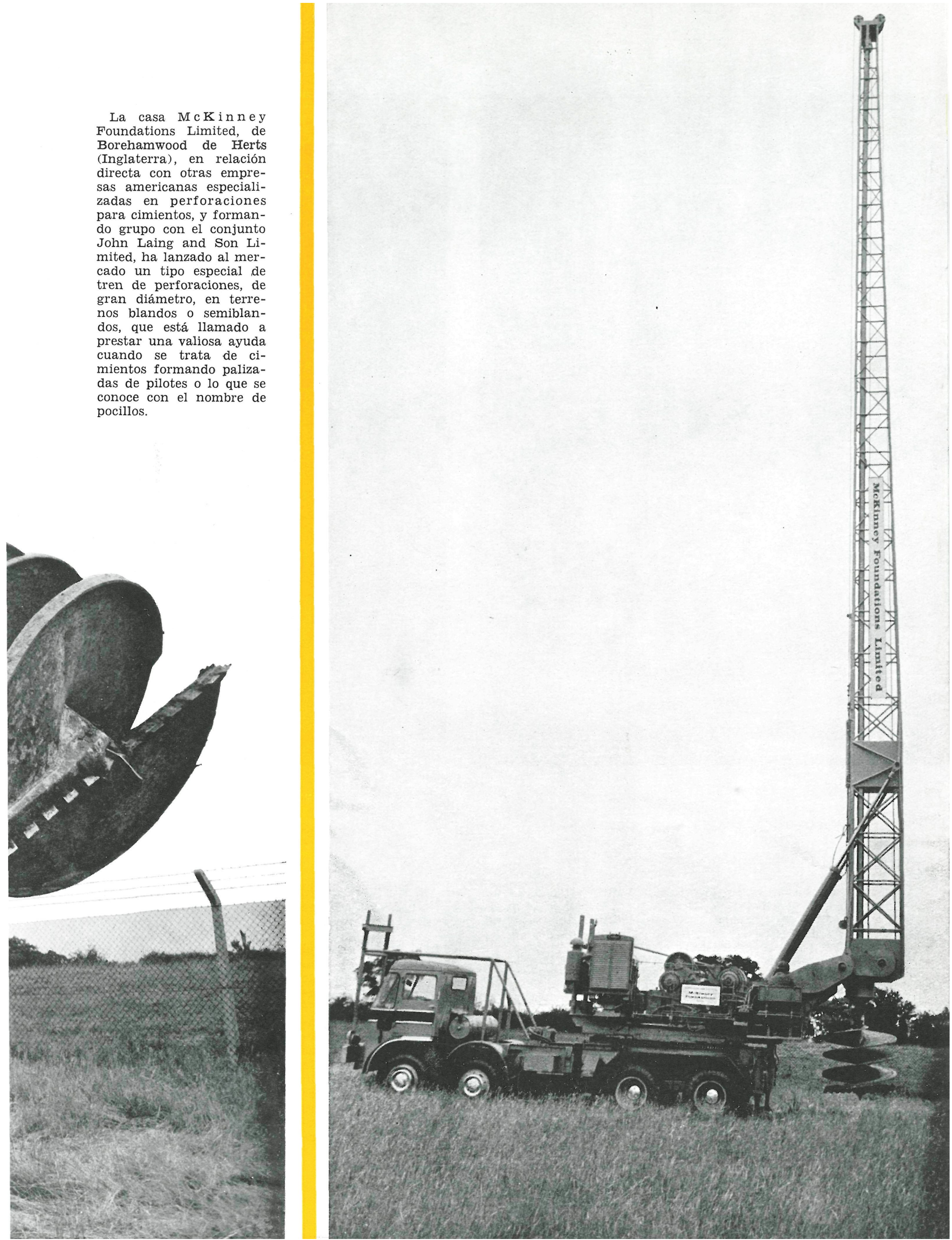

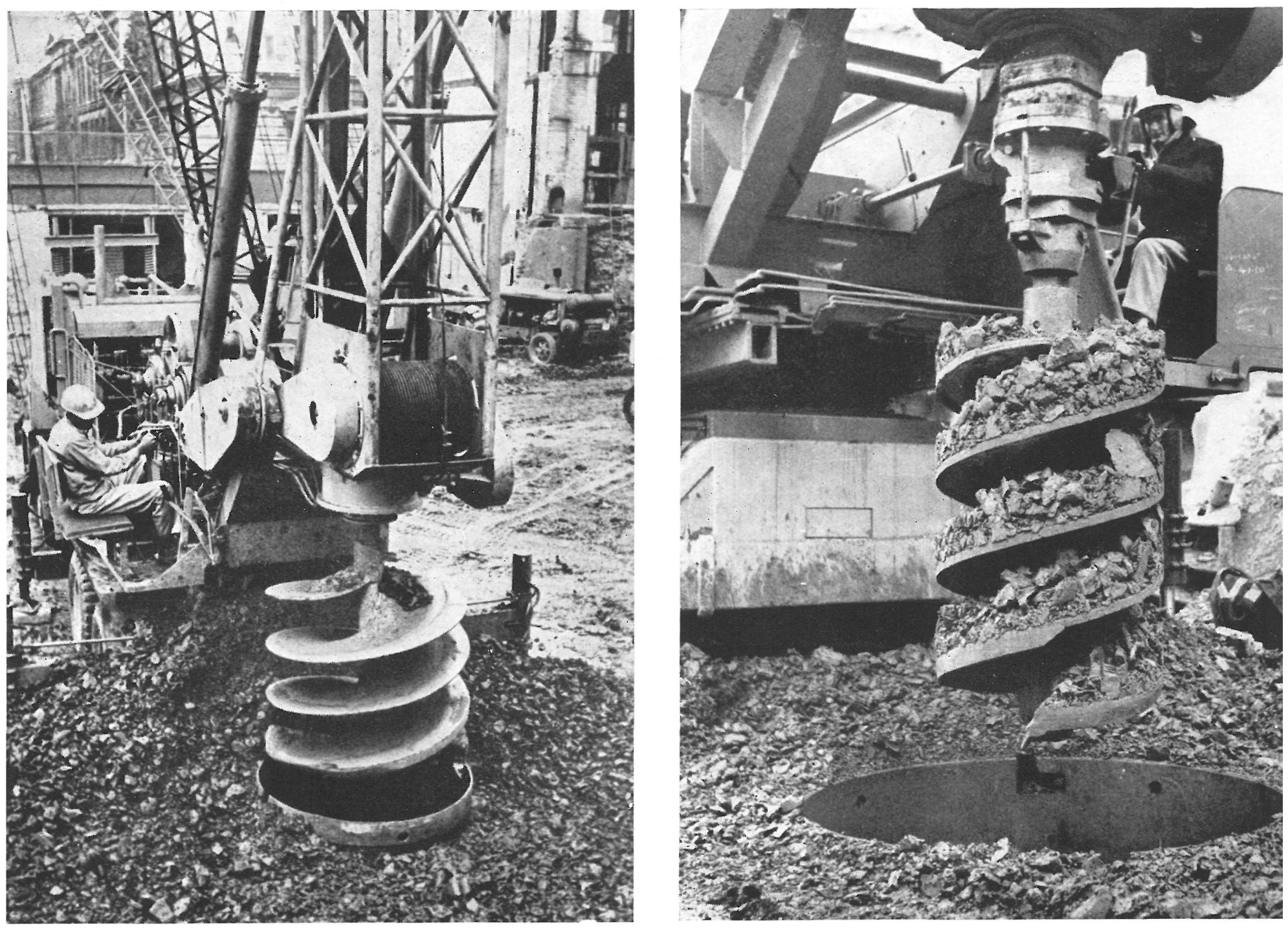

En efecto, en los terrenos homogéneos, en los que el suelo aparece en su espesor próximo a la superficie en forma de arenas arcillosas no excesivamente compactas, es decir, sin llegar a formar bancos rocosos, el pocillo - perforación de gran diámetro, de hasta unos 2,50 metros, constituye la base para levantar un firme pilar de apoyo, pero con una ventaja particular en este caso: la rapidez de su excavación y no tener que volver a rellenar $y$ consolidar el terreno pre- viamente excavado, como viene sucediendo con el procedimiento corriente de abrir zanjas.

Otra notable particularidad de esta sonda espepecial es la posibilidad de ensanchar la parte inferior del taladro para formar una especie de campana, con lo que se aumenta notablemente la superficie de repartición de carga.

Los pocillos sustituyen con ventaja a las perforaciones de pequeños diámetros en los que se for- man "in situ" los pilotes, que se aprovechan también de la adherencia.

Podría presentarse el caso de hallarse ante un terreno poco estable que amenazase con desprenderse; esto se evita fácilmente con una entubación, que puede ser perdida o recuperable. Otras veces también se teme la desecación del hormigón que rellena el pocillo por absorción de los hastiales del mismo, pero esto también se evita con la entubación.
Todo el tren va montado sobre un robusto chasis, en el que se ha instalado todo el aparejo que requiere las maniobras de la torre y sonda de un tren ordinario de sondeo. Dispuesto de esta forma, el tren presenta una gran movilidad para maniobras locales y para los cambios de obra o lugar.

En casos favorables de terrenos apropiados a estas prácticas se pueden conseguir profundidades de hasta $15 \mathrm{~m}$ de profundidad en dos horas. 